\title{
CATAMENIAL PNEUMOTHORAX AND MALIGNANT HYPERTHERMIA
}

\author{
D.J. MCKNIGHT, AND B.M. Marshall
}

THIS ACCOUNT briefly reports a patient presenting two rare disorders affecting the administration of anaesthesia: recurrent pneumothorax and possible malignant hyperthermia. The procedure proposed, diagnostic laparoscopy, required conditions possibly affecting these disorders.

Catamenial (from the Greek K $\alpha \tau \alpha \mu \dot{\eta} \nu \iota \alpha$ menses from $\mu \dot{\eta} \nu$ month) pneumothorax is a syndrome of recurrent spontaneous pneumothorax, almost always right-sided, associated in time with the onset of menstrual flow. Soderberg and Dahlquist' in 1976 brought the total number of reported cases to 41 . In all these women, as in this patient, the pneumothorax occurred within 48 hours of the beginning of menstrual flow.

The aetiology of this syndrome is unknown, but a strong relationship to pelvic endometriosis has been demonstrated. In some of the patients defects of the right hemidiaphragm, presumed to be congenital, have been found, and in a few there have been actual cases of pleural or diaphragmatic endometriosis. ${ }^{2}$ Several mechanisms have been suggested to explain this symdrome. ${ }^{1,2}$

(1) That air may enter the genital tract at menstruation and pass to the peritoneum and thence through a defect in the right diaphragm to the chest. However, at thoracotomy diaphragmatic defects are not found in many of the patients and it is rare to find a pneumoperitoneum at the time of pneumothorax. Induced pneumoperitoneum has failed to produce pneumothorax. ${ }^{3}$

(2) That pleural or pulmonary endometrial implants may allow leakage of air to the pleural space. This is appealing yet these implants cannot be found in all patients.

(3) That prostaglandin $F_{2}$ tromethamine may cause bronchiolar and vascular constriction and result in local rupture of lung damaged by vasospasm.

Whatever the aetiology, there are two recommended forms of treatment: thoracotomy and pleurodesis or hormonal control of the periods. The latter is certainly simpler but is not always

D.J. McKnight, M.D. and B.M. Marshall, M.D., F.R.C.P.(C). Department of Anaesthesia, University of Toronto, and Toronto General Hospital. Toronto, Ontario, M5G 1L7.

Canad. Anaesth. Soc. J., vol. 25, no. 1, January 1978 effective in eliminating pneumothorax. It is also interesting that although few cases have been reported, this syndrome may be more common than has been thought. Shearin ${ }^{2}$ reports 11 of 196 cases of spontaneous pneumothorax in women under 50 years of age were due to catamenial pneumothorax. It is suggested that if this possible relationship between menses and pneumothorax were more widely known it might be found more often in history taking and recognized more often as more than coincidence.

The second problem with this patient, the malignant hyperthermia (M.H.), is now a wellknown albeit rare entity. There are several recent reviews. ${ }^{4,5}$ In the management of this disease, prevention of its occurrence is the major goal. For this reason, all persons with a family history of the disease are treated as if they themselves were afflicted. The anaesthetic requirements for the procedure necessary to investigate catemenial pneumothorax, such as tracheal intubation and mechanical ventilation, necessitated the use of agents and techniques which were complicated by both disease states which this patient presented.

Our patient, a woman of 34 years, gave a history of recurrent episodes of crushing central chest pain radiating through to the back, always related temporally to the beginning of her menses. Each episode began within $\mathbf{4 8}$ hours before or after onset of menstrual flow. The last three of these episodes, one in 1975 and two in 1976, were the most severe and each was documented as spontaneous right-sided pneumothorax. None was severe enough to require a chest tube and each was resorbed within two to three weeks, by which time the pain was relieved.

The patient experienced menarche at age 13, with an overall 28-day cycle with seven days of menstrual flow. There has always been mid-term spotting and recently dysmenorrhea. The patient has never been pregnant.

The family history of malignant hyperthermia is strong. A first cousin died during a general anaesthetic and both parents of this cousin were found to be M.H. positive by muscle biopsy. No other family members have been tested by muscle biopsy, but several have elevated creatine 
phosphokinase (C.P.K.). The patient's C.P.K. was 77 units at this admission (normal serum level for females at this hospital 10 to 90 International Units/liter). The patient's only previous anaesthetic, in 1970, was an uneventful halothane-oxygen anaesthetic for dilatation and curettage which lasted 35 minutes.

After premedication with pantopon $10 \mathrm{mg}$ intramuscularly and diazepam $10 \mathrm{mg}$ per os, anaesthesia was induced using thiopentone $300 \mathrm{mg}$ plus $75 \mathrm{mg}$ and oxygen ( $2 \mathrm{l} / \mathrm{min}$ ) and nitrous oxide (4 $1 /$ min) was delivered through a machine of which the circuits had never been used for halogenated agents. Pantopon $4 \mathrm{mg}$ was added during the operation and relaxation was achieved with pancuronium bromide $4 \mathrm{mg}$. A thoracic surgeon was present throughout the procedure, prepared to insert a chest tube if necessary. Breath sounds and airway pressures were monitored carefully as was axillary temperature. Ice for cooling and emergency drugs were at hand.

At the conclusion of the operation the patient was taken to the recovery room and ventilated mechanically for 90 minutes until good muscle strength returned without pharmacological reversal of muscle relaxants.

Laparoscopy confirmed the diagnosis of endometriosis. Several small islands of endometriosis were found in the pelvis. At the junction of the falciform ligament and the diaphragm there were "several areas of pigmentation with some fat deposition very suggestive of small islands of endometriosis" (from the operative note).

The patient made an uneventful recovery and was sent home on the second post-operative day with hormonal therapy.

\section{Discussion}

This patient demonstrated many of the features characteristic of catamenial pneumothora ${ }^{3}$. She had documented right-sided pneumothoraces within $\mathbf{4 8}$ hours of onset of menstrual flow and at no other time in her cycle. Evidence of endometriosis was found at laparoscopy.

The risk in this anaesthetic was one of iatrogenic pneumothorax caused either by positive pressure ventilation or by hyperinflation of the abdominal cavity with carbon dioxide, both of which were necessary for the procedure. Moreover, although the patient had had irregular cycles, her menses were due to begin about the time of this operation. Close monitoring of airway pressures and repeated clinical examination would have revealed a pneumothorax and preparations had been made to deal with this.

With a family history including one death due to malignant hyperthermia and another relative proven susceptible by biopsy we felt it necessary to approach this patient as if she too were susceptible. A normal C.P.K. value does not rule out M.H. susceptibility as one-third of cases have normal C.P.K. before operation. ${ }^{5}$ Even a previous uneventful anaesthetic is noted in one-third of patients with M.H. reactions, although there is no good explanation for this phenomenon. ${ }^{5,6}$

Induction of anaesthesia with thiopentone after premedication with a narcotic and diazepam is standard practice. There is only slight suggestion that nitrous oxide can initiate M.H., ${ }^{7}$ and this finding has been disputed. ${ }^{8}$ The use of pancuronium is not general practice but work in pigs ${ }^{9}$ and opinions of workers in the field suggest that this is a safe agent. ${ }^{10}$ No pharmacological reversal of relaxation was attempted, however, as there is some evidence that atropine modifies M.H. and increases the incidence of rigidity. "1 The patient was ventilated mechanically in the recovery room until muscle strength returned.

It is very unusual to find two rare diseases in the same patient. However, individually they are among the rare but significant problems in anaesthesia.

It has been suggested that wider discussion of catamenial pneumothorax may result in more frequent recognition and it is to be hoped that this report might further discussion.

\section{SUMMARY}

This paper presents a patient showing both the unusual syndrome of catamenial pneumothorax and a strong family history of malignant hyperthermia. The anaesthetic management is described and discussed.

\section{RÉSUMÉ}

Le pneumothorax cataménial, un syndrome rare, est un pneumothorax droit spontané récidivant, survenant au début des menstruations. Son étiologie est inconnue, mais l'on a pu démontrer une corrélation entre son incidence et la présence d'endométriose (pleurale ou diaphragmatique). Deux traitements ont été recommandés, l'un chirurgical (décortication pleurale), l'autre médical (contrôle hormonal des menstrua. tions).

Ces malades sont donc susceptibles d'être 
anesthésiées pour thoracotomie ou pour laparoscopie diagnostique d'endométriose. Elles risquent à ce moment un pneumothorax iatrogénique secondaire à la ventilation à pression positive ou à la présence d'une pression positive intra-abdominale $\left(\mathrm{CO}_{2}\right.$ utilisé pour laparoscopie).

Les auteurs rapportent le cas d'une patiente atteinte de ce syndrome et présentant une histoire familiale d'hyperthermie maligne. Les précautions prises chez cette malade qui a subi une laparoscopie sans incident sont décrites.

(1) Anesthésie. Prémédication: pantopon 10 $\mathrm{mg}+$ diazepam $10 \mathrm{mg}$. Induction: thiopental 300 mg. Maintien: $\mathrm{N}_{2} \mathrm{O}-\mathrm{O}_{2}(4 / 2)+$ pancuronium 4 $\mathrm{mg}$ I.V.

(2) Monitoring constant du murmure vésiculaire et de la pression des voies aériennes.

(3) Présence en salle d'un chirurgien prêt à insérer un tube thoracique en cas de pneumothorax.

(4) Glace dans la salle pour refroidir la malade en cas d'hyperthermie maligne, et médication appropriée.

\section{ACKNOWLEDGEMENT}

We wish to thank Dr. C.P. Vernon for his kind permission to publish this report.

\section{REFERENCES}

1. Soderberg, C.H. \& Dahlquist, E.H. Catamenial pneumothorax. Surgery 79: 236 (February 1976).

2. Shearin, R.P.N., Hepper, N.g.G. and Payne, W.S. Recurrent spontaneous pneumothorax concurrent with menses. Mayo Clin. Proc. 49: 98 (February 1974).

3. Lillington, Mitchel, \& Wood. Catamenial pneumothorax. J.A.M.A. 219: 1328 (1972)

4. BritT, B. Malignant Hyperthermia. Modern Medicine 31: 511 (1976).

5. RYAN, J.F. Malignant hyperthermia, etiology and treatment. A.S.A. Refresher Courses (1976).

7. ELLIS, F, R., et al. Malignant hyperpyrexia induced by nitrous oxide and treated with dexamethasone. Br. Med. J. 4: (5939) 270 (2 Nov. 1974).

8. LUCKE, J.N., et al. Malignant hyperpyrexia. Letter Br. Med. J. I: (5955) 545 (22 Feb. 1975).

9. HALL, G.M., ef al. Neuromuscular blocking of drugs in porcine malignant hyperthermia. $\mathrm{Br} . \mathrm{J}$. Anaesth. 48: 270 (1976).

10. BritT, B. Personal communication.

11. BRITT, B. \& KALOW, W. Drugs causing rigidity in malignant hyperthermia. Letter, Lancet 2: 390 (1973). 